http://jmscr.igmpublication.org/home/ ISSN (e)-2347-176x ISSN (p) 2455-0450 crossref DOI: https://dx.doi.org/10.18535/jmscr/v8i2.05

\title{
A Rare Case of Mitral Stenosis with Ortner's Syndrome-A case Report
}

\author{
Authors \\ Padma Guduri ${ }^{1^{*}}$, Dr Gandhi. ${ }^{2}$, Dr Tarunshiva..$^{3}$ \\ GSL medical college, Rajanagaram, Rajahmundry 533296 Andhra Pradesh, India \\ *Corresponding Author \\ Padma Guduri
}

\begin{abstract}
Rheumatic mitral stenosis is prevalent in this part of the world, and it gives rise to a wide array of manifestations. Most patients with moderate to severe mitral will have some degree of left atrial enlargement due to chronic increases in left atrial pressures, predisposing them to atrial fibrillation and thromboembolic events. Left vocal cord palsy and dysphagia are uncommon complications. With a reduced incidence of mitral valve disease from rheumatic fever, the incidence of left atrial enlargement has also decreased. Ortner's syndrome or Cardiovocal syndrome is characterized by hoarseness of voice which is caused by the paralysis of left recurrent laryngeal nerve as a result of cardiovascular causes.
\end{abstract}

Keywords: Mitral stenosis, Ortner's syndrome, vocal cord palsy, Cardiovocal syndrome, left atrial enlargement.

\section{Introduction}

Mitral stenosis is a valvular lesion typically seen in adults as a result of childhood rheumatic carditis, and if the valve lesion is unrecognized and untreated, it can lead to left atrial dilation, atrial fibrillation and potentially fatal complications can occur. Left vocal cord palsy and dysphagia are uncommon complications. These complications are hardly seen nowadays as intervention is taken early in its course. Cardiovocal syndrome or Ortner's syndrome is hoarseness due to left recurrent laryngeal nerve paralysis in patients with mitral stenosis and left atrial enlargement was first described in 1897 by Nobert Ortner. The incidence of Ortner's syndrome varies between $0.5-0.6 \%$. The common lesions that cause Ortner's syndrome include Mitral stenosis, Pulmonary Hypertension, Aortic aneurysm. Early recognition and treatment along with removal of the underlying cause, if possible, may change an otherwise poor prognosis of the condition.

\section{Case Report}

A 39-year-old non diabetic and non-hypertensive patient presented to our hospital 7 months' history of shortness of breath (NYHA class III), palpitations, and hoarseness of voice since 3 months low-grade intermittent fever of 5 days duration. There was no history of orthopnoea or paroxysmal nocturnal dyspnoea. On general examination pulse was regular, low volume with a rate of $78 / \mathrm{min}$ and blood pressure was $100 / 60 \mathrm{~mm}$ hg. Cardiovascular examination revealed apex beat was present in the fifth intercostal space and which was taping in nature. On auscultation, first heart sound loud and a grade 3/4 low pitched rumbling mid-diastolic 


\section{JMSCR Vol||08||Issue||02||Page 17-19||February}

murmur with opening snap heard at mitral area. Per abdomen, Respiratory, CNS examination were normal. Blood investigations revealed $\mathrm{HB}-14.5 \%$, PCV- 45.4, RBC 5.1 lakhs/cu mm, WBC- 12,500 cells/cu mm. Chestx-ray showed cardiomegaly, left atrial enlargement. Echocardiography showed CRHD, grossly dilated left atrium, calcific Aortic valve, Severe Mitral stenosis, Moderate pulmonary artery hypertension (RVSP $=44 \mathrm{mmhg}$ ), and Ejection fraction was $41 \%$. Video laryngoscope revealed left vocal cord palsy in Para median position. The clinical symptoms in combination with imaging findings, were consistent with Ortner's syndrome. The patient underwent mitral valve replacement and his hoarseness of voice recovered after a few months. He is asymptomatic on follow up.

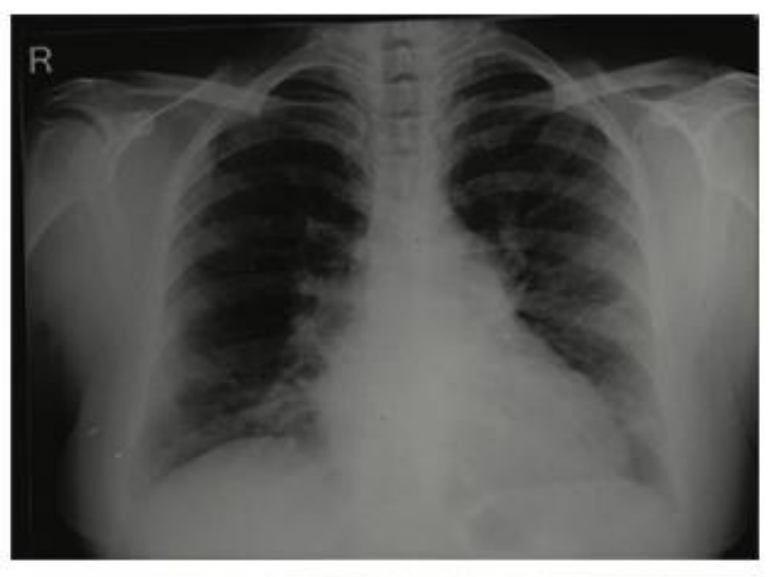

Fig 01

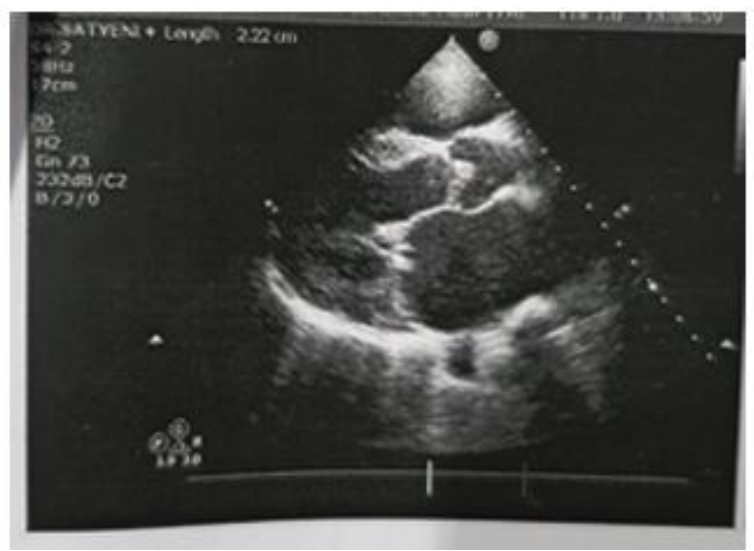

Fig 02

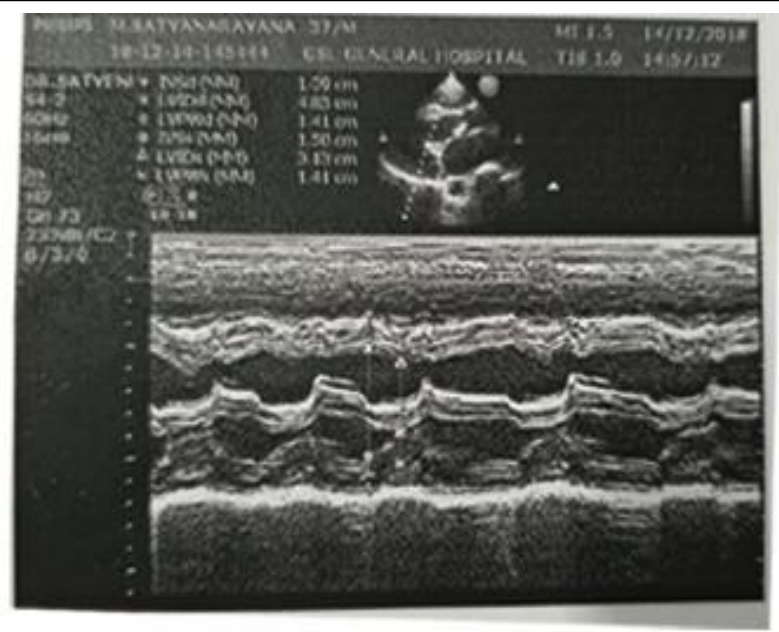

Fig 03

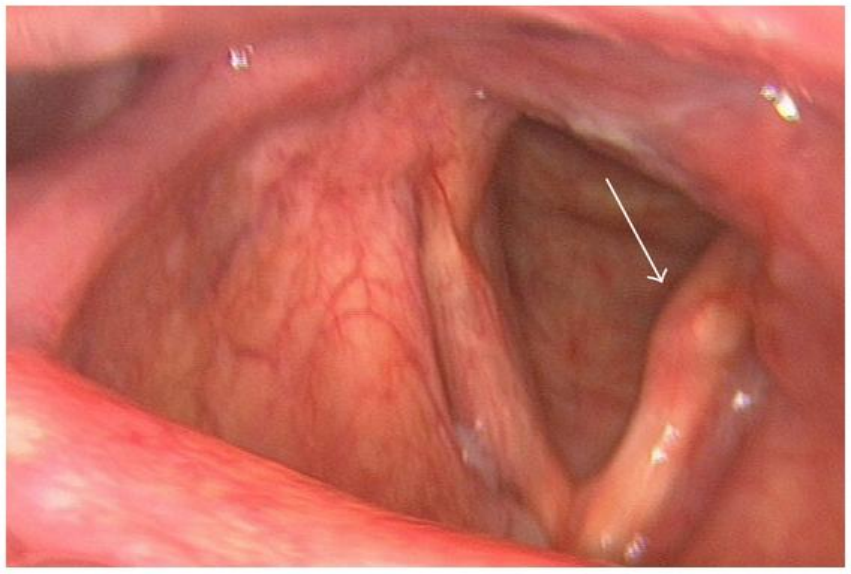

Fig 04

\section{Discussion}

Cardio vocal syndrome was originally described in 1897 by Nobert Ortner in three patients with severe mitral stenosis. ${ }^{[1]}$ He explained that hoarseness was caused by compression of the left recurrent laryngeal nerve by the enlarged left atrium. Later it has been encountered with other mediastinal structures causing mass effect ${ }^{[2]}$ and in many cardiac conditions, for example, congenital heart diseases, mitral valve disorders, ventricular and aortic aneurysms, atrial enlargement and in iatrogenic conditions. ${ }^{[3]}$ Cardiovocal syndrome caused by idiopathic pulmonary artery hypertension and dilated pulmonary trunk has also been described in the literature. ${ }^{[4]}$ To the best of our knowledge Cardiovocal syndrome associated with pulmonary embolism is a very rare condition and it has been described only twice. 
The pathophysiological mechanism of this syndrome is thought to be compression of the left recurrent laryngeal nerve between the left atrium and dilated pulmonary artery. Chest radiograph is usually ordered as the first imaging study. Echocardiogram helps in identifying structural abnormalities of cardiac structures like left atrial dilation, pulmonary artery enlargement etc. Neck and chest CT or MRI should be done in patients with no laryngeal cause of hoarseness is identified and if echo is normal. As we have ruled out, laryngeal causes of hoarseness and ECHO showed hugely dilated left atrium and pulmonary artery, we have not done CT/MRI. ${ }^{[5]}$

Early recognition of the cause of the left recurrent laryngeal nerve palsy is the most important part of the treatment because reversibility of the nerve damage depends on the duration of injury. ${ }^{[6]}$ Prognosis of Ortner syndrome depends on the underlying etiology as well as the duration of illness. There are few case reports where there is significant improvement in hoarseness of voice after mitral valvotomy/MVR. But in our case hoarseness of voice recovered in a few months after mitral valve replacement.

\section{Conclusion}

Ortner's syndrome or Cardiovocal syndrome is characterized by hoarseness of voice, which is caused by the paralysis of left recurrent laryngeal nerve as a result of cardiovascular causes.Early recognition of the cause of the left recurrent laryngeal nerve palsy is the most important part of the treatment because reversibility of the nerve damage depends on the duration of injury.

\section{References}

1. N. Ortner, "Recurrensslähmungbei mitral stenose," Wien Klein Wochenschr, vol. 10, pp. 753-755, 1897.View at: Google Scholar

2. S. C. Plastiras, C. Pamboucas, T. Zafiriou, N. Lazaris, and S. Toumanidis, "Ortner's syndrome: a multifactorial cardiovocal syndrome," Clinical Cardiology, vol. 33, no.
6, pp. E99-E100, 2010.View at: Google Scholar

3. K. Mulpuru, B. C.,Vasavada, G. K. Punukollu, and A. G. Patel, "Cardiovocal syndrome: a systematic review," Heart Lung and Circulation, vol. 17, no. 1, pp. 1-4, 2008.View at: Publisher Site/ Google Scholar

4. M. Nakahira, H. Nakatani, and T. Takeda, "Left vocal cord paralysis associated with long-standing patent ductus arteriosus," American Journal of Neuroradiology, vol. 22, no. 4, pp. 759-761, 2001.View at: Google Scholar.

5. H.S. Glazer, D.J. Aronberg, J.K. Lee, S.S. S agel Extra laryngeal causes of vocal cord paralysis: CT evaluation, AJR Am J Roentgenol, 141 (1983),pp. 527-531 .

6. J. Heikkinen, K. Milger, E. AlejandreLafont, C. Woitzik, D. Litzlbauer, J.F. Vogt, et al. Cardiovocal Syndrome (Ortner's Syndrome) associated with chronic thromboembolic pulmonary hypertension and giant pulmonary artery aneurysm: case report and review of the literature Case Rep Med, 2012 (2012), p. 230736 